ROAD PRICING SCHEMES: POLICY LESSONS FROM

THE BAY BRDIGE IN SAN FRANCISCO

by

Bachelor of Arts (Honours), Trent University, 2017

A Major Research Paper
presented to Ryerson University
in partial fulfillment of the requirements for the degree of

Master of Planning

in

Urban Development

Toronto, Ontario, Canada, 2020

(C) Paul Brioux 2020 


\section{Author's Declaration}

I hereby declare that I am the sole author of this MRP. This is a true copy of the MRP, including all required final revisions.

I authorize Ryerson University to lend this MRP to other institutions or individuals for the purpose of scholarly research.

I further authorize Ryerson University to reproduce this MRP by photocopying or by other means, in total or in part, at the request of other institutions or individuals for the purpose of scholarly research.

I understand that my MRP may be made electronically available to the public. 


\title{
ROAD PRICING SCHEMES: POLICY LESSONS FROM \\ THE BAY BRDIGE IN SAN FRANCISCO
}

\author{
Paul Brioux, 2020 \\ Master of Planning in \\ Urban Development Ryerson University
}

\begin{abstract}
As cities develop and urbanize, and space becomes increasingly valuable, additional pressures are placed on all systems including transportation. Road pricing has been used to generate revenue, mitigate congestion, and reduce pollution. However, implementing road pricing schemes has been difficult, given its contentious nature.

This study begins by providing a brief literature review of road pricing and highlighting lessons from key road pricing schemes that have emerged throughout the last twenty years. While previous studies have been explored extensively for their successes and limitations, the Bay Bridge has been comparatively understudied. The Bay Bridge showcases atypical characteristics that have influenced construction and pricing structures throughout its history. Given multiple case studies, and a more in-depth knowledge of the Bay Bridge, the current study identifies lessons that can be applied for the Bay Bridge as it continues to evolve and for the broader future of road pricing internationally.
\end{abstract}

Key words: Road Pricing, Congestion Charging, Pollution Mitigation, Public Opinion, Variable Pricing 


\section{Acknowledgements}

I would first like to extend my sincere thanks to my supervisor, Professor Matthias Sweet, for helping guide me through this process and for sharing his extensive knowledge in the vital field of transportation planning. His feedback and willingness to talk and inform my varying scope was indeed invaluable throughout the MRP process.

Similarly, I'd like to thank my second reader, Professor Sean Hertel, for his encouragement and willingness to mentor me throughout the last year of my degree. Sean has been very helpful for me as I endeavour to transition from the academic rigours of university to the planning workforce and all that may entail.

Finally, I'd like to thank my parents Mike and Liz for their ongoing support, for which I am extremely grateful and will always appreciate. 
Table Of Contents

1.0 Introduction 1

2.0 Literature Review 2

2.1 Singapore 3

2.2 Bergen, Norway 5

2.3 Oslo, Norway

2.4 Trondheim, Norway 10

2.5 London, England 12

2.6 Stockholm, Sweden $\quad 14$

2.7 Milan, Italy 17

2.8 International Case Studies — Common Themes 20

$\begin{array}{ll}3.0 \text { The Bay Bridge Case Study } & 24\end{array}$

3.1 Public Input 25

3.2 Policy Objectives $\quad 26$

3.3 Post-Earthquake Seismic Retrofitting 28

3.4 Policy Shifts: Congestion Alleviation 31

$\begin{array}{ll}4.0 \text { Conclusion and Lessons } & 34\end{array}$

4.1 Adapt Implementation Strategies $\quad 35$

4.2 Public Interest and Electability 36

4.3 Public Opposition and Purpose Road Pricing 36 


\subsection{Introduction}

Road pricing has substantial potential to address a variety of common issues cities face.

However, it is a contentious practice and its implementation often brings controversy.

Governments are hesitant to proceed with such interventions when public resistance to the addition of user fees remains high. Many times, politicians have acted against public opinion to implement road pricing schemes and realize their full benefits. Case studies that have implemented these measures are important for understanding the potential for road pricing, often exemplifying when this potential far exceeds the necessity for politicians to act on their own self interest and goals can instead be achieved through otherwise safe political decision making.

In one understudied case study (the topic of this MRP), the original construction of the Bay Bridge in San Francisco relied on public opinion to incentivize politicians, which is atypical when compared to other schemes. Due to San Francisco's unique location on a peninsula, very few connections exist between the city centre and nearby Oakland - making each available connection even more important. In fact, public opinion generally supported road pricing as a means to finance the bridge's construction due to expected cost savings compared to other alternatives.

Since 1932, the bridge has imposed road pricing measures, which has led to normalized road pricing in the the Bay Area. After the Loma Prieta earthquake destroyed sections of the bridge, expensive seismic relief construction and new funding tools were required. Moreover, as congestion has increased, the bridge's pricing structure had been further adapted to balance the relative policy priorities to generate revenues or manage congestion. 
While previous case studies have explored the potential for road pricing to address local planning issues, the Bay Bridge in San Francisco has been comparatively understudied as a scheme that balanced several policy objectives. This study begins by providing a literature review on road pricing. Several common case studies are discussed to explore how the theory of road pricing relates to practice. Finally, a case study is completed to showcase the potential that exists for San Francisco to achieve its congestion reduction, revenue generation, and construction goals through varying road pricing implementation. Lessons are proposed on how the Bay Bridge can provide guidance for other regional contexts considering road pricing.

\subsection{Literature Review}

Road pricing can have multiple purposes including revenue generation, congestion mitigation, and pollution reduction. In urban centres, space becomes increasingly valuable, which places varying pressure on all systems including transportation. Road pricing can improve vehicular flow by aligning the marginal cost of using infrastructure with the full costs incurred on other users through congestion. Many cities have implemented and tested a variety of road pricing schemes and have had varying levels of success. They provide examples of changing priorities to address revenue generation, congestion mitigation, and air pollution. Before delving into the Bay Bridge case study in more depth, seven case studies are presented to illustrate how road pricing can be implemented to achieve various impacts. Air pollution, congestion mitigation, and revenue generation - all of which divert varying funds to other purposes — are showcased with varying successes. 


\subsection{Singapore}

Like other urban centres, Singapore has experienced a growing population with increasing daily trips into the Central Business District (CBD). With the additional development around the city, the number of vehicle trips rose from 275,000 in 1975, to 750,000 in 1998 (Eliasson et al, 2013). Public transportation use also grew by 63\% (Eliasson et al, 2013). Given increasing trips for both public transportation and vehicular use, congestion within the CBD emerged as a growing concern for government officials.

In 1975, a road pricing scheme known as an Area Licensing Scheme (ALS) was created with the purpose of reducing congestion in the $\mathrm{CBD}$ and therefore improving reliability and predictability for drivers (Eliasson et al, 2013). A pricing scheme was created for entering the two square mile area known as the restricted zone, and was in force between 7:30 a.m. and 9:00 a.m. with a \$1.30 USD charge (Eliasson et al, 2013). Drivers had to pre-pay and provide proof of this payment by presenting the license of payment on windshields (Eliasson et al, 2013).

To further address and achieve congestion mitigation goals with ever-increasing vehicular travel, this system was adapted in 1998, and saw with it the creation of an electronic road pricing model or ERP (Eliasson et al, 2013). Additionally, this created a new and larger cordoned area while also incorporating an electronic payment structure that allowed for different tolling strategies. Road pricing was also enforced with expanded hours operating from 7:00 a.m. to 2:00 p.m., Monday through to Saturday (Tristate Transportation Campaign, 2017).

By this time, the ERP was fully automated, with no physical tolling booths as typically seen in other systems. To achieve this, Singapore built overhead tolling stations on major roads, which created a cordon area with overhead tolling. The overhead tolling connected to an in- 
vehicle unit on the dashboard, requiring a smart card with a fare bought and stored on it (Tristate Transportation Campaign, 2017). Individuals were then further required to purchase the invehicle unit at a cost of $\$ 111.00$ USD, which allowed tolls to be automatically paid en route (Tristate Transportation Campaign, 2017).

To address variable demand, Singapore created a system with charge points or tolling locations around the city that has the ability to change the toll price (Eliasson et al, 2013). Creating a variable toll structure has allowed the city to charge a fee more reflective of the true marginal cost, which varies from 0 to $\$ 3.00$ (Tristate Transportation Campaign, 2017). Urban transportation economists widely regard this system as the most efficient for road pricing, given its ability to reflect the true marginal cost through updated real-time tolling that is accurately reflected (De Palma \& Lindsey, 2009). Real-time tolling can change price depending on location or time of day and provide further control over current conditions, increasing efficiency of roadways by decreasing congestion

With the introduction of the adapted ALS, Singapore created additional infrastructure to facilitate the feasibility of travelling into the city centre without a car. Creating new Park and Ride lots with specific shuttle service into the restricted zone resulted in $33 \%$ increased access to bus services and saw parking rates decrease by $30 \%$ in the restricted zone (Eliasson et al, 2013). Not only did these specific interventions complement the ERP system, these modifications helped provide options for commuters by increasing service while also creating automobile travel disincentives.

To create the infrastructure needed to facilitate the ERP system, an initial investment of 110 million USD was required (Tristate Transportation Campaign, 2017). The higher initial cost 
was offset by a relatively lower annual cost of 18.5 million USD, which has had positive effects at mitigating congestion within the city. Although the purpose for this system was to reduce congestion for automobile users exclusively, the system generates roughly USD \$100 million per year, while positively impacting overall congestion mitigation (Tristate Transportation Campaign, 2017). Revenue generation and successful impacts on congestion contribute to ERP's feasibility and long-term viability due to positive metrics.

The road pricing system implemented in Singapore had positive congestion mitigation outcomes even with an increasing population. The imposed tolling charge decreased congestion in the cordoned area by $25 \%$ and also had positive impacts on the bus system that rose in use by 15\% (Tristate Transportation Campaign, 2017). The dynamic nature of the charge allowed the city to adapt to changing conditions and provided positive congestion mitigation results.

\subsection{Bergen, Norway}

The potential for road pricing to address congestion and revenue generation has been incorporated into policy and implementation for different Norwegian cities. Projects in the country's three largest cities (Bergen, Oslo, and Trondheim) have similar implementation characteristics through the use and tolling of ring roads surrounding each city. These schemes have been used with differing scales as financial instruments for road construction, funding generation for public transportation, and congestion mitigation. The three case studies exhibit the importance for differing scales of implementation, and the role of public opposition as a tool for feasibility of such schemes.

In 1986, Bergen was the first city in Norway to establish road pricing (Leromonachou et al, 2006). Historically, Bergen's car ownership rates were one of the lowest in Norway with 345 
vehicles per 1,000 inhabitants (Sorstrom, 1999 as cited in Leromonachou et al, 2006). This was due to limiting parking capacity given the lack of parking spaces around the city centre, which also made parking relatively expensive for both frequent and infrequent drivers alike (Leromonachou et al, 2006). This allowed the city to carefully control congestion and helped to ensure parking spaces would not invite increased car capacity within the city.

Throughout the 1970s, and early 1980s, however, Bergen had increasing congestion issues within the city centre, with vehicle noise and air pollution becoming unsustainable (Leromonachou et al, 2006). During this time, a new master plan was created with priorities that looked to reimagine roads from the west and the north — roads that would connect three transportation corridors and parking capacity within the city (Lain, 2008). To raise the necessary funds for these investments and properly implement the master plan, funding was necessary. However, initial projections showed that conventional funding techniques would take 30 years for such plans to be implemented (Leromonachou et al, 2006). The city, therefore, decided to develop a road pricing scheme that would allow revenue generation created from the scheme to pay for such improvements, calling them 'tolls' (Leromonachou et al, 2006).

Prior to implementation, there existed a negative public perception to applying road pricing measures to public roadways around the city. Given the relatively high expense in Norway for purchasing cars, road taxation, insurance, and other taxing structures, citizens felt pricing would affect them too drastically (Leromonachou et al, 2006). Public opposition to the project persisted, however, and due to the need for infrastructure improvements, local politicians introduced road pricing measures regardless (Leromonachou et al, 2006). 
The tolling locations were close to the city centre, with one-way collection for drivers travelling into the city (Lain, 2008). This addition reduced the ability for drivers to evade tolls a vital component of the project as revenue generation was the purpose behind the pricing structure. To further minimize unfavourable reactions to the creation of road pricing, Bergen kept original toll prices low at $5 \mathrm{NOK}$, but allowed further increasing to $15 \mathrm{NOK}$ (Lain, 2008). The pricing period's original charging hours of 6:00 a.m. to 10:00 p.m. were soon updated to charge 24-hours a day, with the goal of easing the public into road pricing (Lain, 2008).

The project reinvested 2.5 billion NOK of the generated revenue between 1986-1997, (Leromonachou et al, 2006) providing citizens with the opportunity to experience the physical benefits of the road pricing system and increasing public perceptions for the road pricing scheme (Lain, 2008). While the project was successful at generating 220 NOK annually as much-needed revenue for infrastructure projects, the project fell short in its congestion limitation ability (Wærsted, 1992 as cited in Leromonachou et al, 2006). Traffic impacts showed a 5-7\% reduction in Bergen but an increase in overall traffic in the region at 3-5\% per year (Leromonachou et al, 2006). For the city of Bergen, the pricing scheme was not created to specifically address congestion alone. The primary outcome was revenue generation, and Bergen was indeed successful in creating this new revenue stream.

\subsection{Oslo, Norway}

Oslo, the capital of Norway, implemented similar ring road tolling in 1990, but with some key differences. Oslo City Council had the opportunity to learn about and address some of the key issues Bergen experienced before implementing a ring road tolling system of their own. Road pricing's potential to have an effect on both traffic congestion and revenue generation was 
both discussed. Council decided that the pricing structure could not adequately balance revenue generation and traffic reduction. As it was necessity for road pricing to generate revenue for infrastructure projects, traffic reduction was therefore scrapped from the goals of the system (Leromonachou et al, 2006). To further increase public transportation use, Oslo City Council incorporated and earmarked $20 \%$ of the revenue for specific public transportation investments designed to help create and maintain dedicated bus lanes, terminals, new metro lines, and services (Leromonachou et al, 2006). This created a much more holistic approach to road pricing, which the initiative in Bergen lacked.

The objective of the tolling strategy in Oslo addressed the growing need to enlarge road capacity with specific funds highlighted for tunnel construction across the capital (Leromonachou et al, 2006). Norway's rocky topography typically results in high costs for construction of infrastructure projects, placing additional pressures on funding mechanisms required to pay for the needed infrastructure (Waersted, 2005).

This project, similarly to Bergen's project, was met with rising public opposition. The public felt they paid enough for roadways and saw this additional fee as an unnecessary extra cost (Leromonachou et al, 2006). The local politicians, however, disagreed with the public and saw the potential for this scheme to pay for infrastructure projects that would otherwise not be fully realized due to the associated costs (Leromonachou et al, 2006). Like in Bergen, once the road pricing system was complete, opinions shifted slightly. After the first year, $65 \%$ of the populous opposed road pricing, a marked decrease from $70 \%$ polled prior to road pricing implementation (Odeck and Brathen, 2002 as cited in Leromonachou et al, 2006). After the second year of operation, as more people became more familiar with the new system, overall 
opposition decreased, showing an average between 55\% and 60\% (Odeck and Brathen, 2002 as cited in Leromonachou et al, 2006).

Interestingly, politicians in Oslo began to see the potential for road pricing to outweigh public opposition, individual acceptance rates, and possible re-election of city politicians in order for the project to be completed. To further decrease initial opposition to the road pricing scheme, toll pricing was lowered and met with success (Waersted, 2005).

To generate the revenue needed to fund the various infrastructure projects, tolls were placed on ring roads surrounding the city, varying between 3 kilometres to 8 kilometres from the city centre (Leromonachou et al, 2006). Casting this wide net provided for a large area where drivers had little ability to avoid payment since they would be forced to pass the toll ring when driving from one part of the city to the other (Lain, 2008). The price was originally set at 10 NOK, but was later raised to $20 \mathrm{NOK}$ (Lain, 2008).

The road pricing scheme required an initial investment of 250 million NOK, which generated a respectable 750 million NOK in the first year (Leromonachou et al, 2006). The operational costs were kept low due to the public ownership model and by incorporating an electronic payment system, which was successfully put in place after opening with initial cash payments only for tolling (Leromonachou et al, 2006). Viewed favourably, the project generated 1192 million NOK between 1990 and 2006, improving both infrastructure creation and servicing abilities for public transportation with $20 \%$ of revenue diverted (Leromonachou et al, 2006)

The ring road tolling scheme was created and is maintained to support revenue generation, versus reducing congestion and car travel. It was successful in doing so, and 
provided for the additional ability to fund public transportation, making this a far more comprehensive model for road pricing than was seen in Bergen.

\subsection{Trondheim, Norway}

Trondheim opened a ring road tolling system in October 1991, shortly after Oslo and Bergen (Waersted, 2005). The tolling system in Trondheim built upon elements in both Oslo and Bergen but with more complexity. It differentiated between the other systems through its operation costs and pricing model, adopting a more holistic approach with other complementing policy initiatives and a promise to be a capped as a 15-year program.

The purpose of road pricing in Trondheim was to address funding generation, which would be applied to large road infrastructure projects around the city (Gómez-Ibáñez \& Small as cited in Bhatt et al 2008). As seen in Oslo, roughly $18 \%$ of revenue was invested in public transportation in conjunction with other environmental improvement projects (Tretvik, 2007). As a city with a smaller population, Trondheim held system efficiency in highest importance (Bhatt et al, 2008). The city's small traffic volumes made conventional 'manned' toll booths both inefficient and uneconomical (Bhatt et al, 2008). To address this problem specifically, automatic coin machines and electronic payments schemes were created. This electronic system was the same as the one implemented in Oslo, but only two of the toll stations in Trondheim were manned (Waersted, 2005). These specific interventions minimized operational costs while allowing users to pass stations quicker and easier than when using physical payment methods. Although the main purpose of the tolling strategy was to generate revenue, local government officials began to see the potential for demand management and therefore traffic mitigation. To address this additional purpose, Trondheim adapted the pricing model with the 
inclusion of varying pricing zones and peak pricing. The scheme first implemented a basic toll of 10 NOK, with heavy cars (above 3,500 kilograms) being charged 20 NOK for only inbound crossings of the ring tolling stations (Tretvik, 2007). Prices were higher during peak morning hours and were free after 5:00 p.m. and on weekends (Tretvik, 2007). Similarly, no monthly pass was available during the first couple years of the basic program (Tretvik, 2007).

In 1998, Trondheim's City Council revised the tolling scheme, dividing the city into six zones while revising the fee structure to extend charging hours from 5:00 p.m. to 6:00 p.m. (Tretvik, 2007). The monthly pass was also incorporated as was the ability to purchase a package of allowable crossings, which would provide a maximum amount of chargeable crossings per month (set at 75) (Tretvik, 2007). The purpose behind these changes was to generate more revenue necessary for the transportation investment plan while also making the fare structure more equitable (Tretvik, 2007).

Prior to the implementation of the road pricing initiative in Trondheim, public perception of the project was poor, with a majority of the public opposing the scheme. In fact, $70 \%$ of the general public opposed the scheme when it was first announced; however, with more information about the scheme being released to the public, opposition dropped to roughly $50 \%$ (Odeck and Brathen as cited in Leromonachou et al, 2006). Public and local retailers in Trondheim's old city centre feared the impact that road pricing schemes might have on customer retention and therefore businesses sustainability. To address the growing concerns and reduce public opposition, City Council created a special policy to improve and preserve existing retail. The policy addressed sprawl by limiting development of new retail on outer sections of the city and further enhanced retail and business in the city centre, making the area more pedestrian friendly 
and attractive to visitors (Leromonachou et al, 20060. In addressing these concerns, and outlining the necessity for revenue generation, public perception rose to $37 \%$ positive, and $35 \%$ negative, with the remainder undecided (Tretvik, 2007).

Toward 2003, public perception was strongly against road pricing due to the introduction of new charging stations placed closer to the city centre (Tretvik, 2007). There was a varying acceptance rate that ran more negatively and could have been attributable to the increasing annoyance with road pricing around the city. The project generated an annual income of 210 million NOK, which was reinvested into local projects around the city (Leromonachou et al, 2006). As Council promised prior to the road pricing scheme, the tolls were lifted and the roadways became toll-free in 2005, providing further levels of trust between the public and government (Leromonachou et al, 2006).

\subsection{London, England}

London was the first European mega-city to address congestion mitigation through a road pricing scheme (Litman, 2011). As London grew and became wealthier, more people turned to car travel for their transportation needs. However, this had subsequent effects on congestion within the city centre. Traffic speeds in London decreased over time from an average of 12.7 mph for peak morning travel in 1968 to $10 \mathrm{mph}$ in 1998 (Leape, 2006). These decreases were even more apparent within the city centre, where the average travel speed was just $8.6 \mathrm{mph}-\mathrm{a}$ stark comparison to an un-congested or free flow average speed of roughly $20 \mathrm{mph}$ (Leape, 2006). 
Negative public perception about increasing congestion levels helped force government action. In 1999, an independent survey found that Londoners felt public transportation to be the most important problem government should address (Leape, 2006).

Congestion mitigation was first prioritized, with revenue generation being an additional element to the scheme. To address these concerns, road pricing was created in 2003, imposing a $£ 5$ daily charge for driving within the congestion zone between 7:00 a.m. and 6:30 p.m., Monday to Friday (Leape, 2006). These prices would rise further to $£ 8$ in 2005 , $£ 10$ in 2011 , and $£ 11.50$ in 2014 to address growing demand and the potential for congestion mitigation (Leape, 2006).

Like other large metropolitan areas, London relies on a diversity of revenue generation capabilities to realize the full potential of its regional transportation needs. In transitioning from congestion limitation to increasing toll prices, the revenue generation resulted in the addition of 300 new buses, new bus routes through both bus-only lanes and shared lanes, and increasing frequency of existing routes in the London region (Tristate Transportation Campaign, 2017). The additional funding was used to create viable options within and outside of the congestion zone and afforded more predictable schedules and commute times for both transit riders and drivers.

The cordon pricing scheme uses overhead cameras to photograph license plates and bill according to registration address (Tristate Transportation Campaign, 2017). This has allowed the city to effectively place a price on the use of driving in the urban centre. Given London's built form, and particularly given its road network design (Litman, 2011), the cost of implementation was minimized due to relatively few entry points and associated infrastructure needed.

The creation of the cordon system required an initial investment of USD \$214 million necessary to create the proper toll infrastructure (Tristate Transportation Campaign, 2017). The 
congestion charge subsequently generated USD \$3.9 billion from 2003 to 2013 with USD\$1.8 billion invested into public transportation, road and bridge improvements, and schemes for increasing cycling/walking during this period (Tristate Transportation Campaign, 2017). A further \$USD1.44 billion was specifically invested to address the surface-level bus network (Tristate Transportation Campaign, 2017).

With increasing funding and congestion reduction, reliability and predictability for all transportation modes within the cordon area improved. Congestion decreased by $30 \%$ as seen prior to road pricing, due to both additional costs of road use but also public feasibility for bus through inclusion of priority bus lanes (Tristate Transportation Campaign, 2017). Passengers entering the congestion zone by bus increased by 29,000 or $38 \%$, due to improved bus service and decreased congestion (Leape, 2006). Through these measures, the London congestion charge was able to increase reliability and predictability while funding surface-level bus systems and other transportation projects to further efforts toward congestion mitigation.

\subsection{Stockholm, Sweden}

Like London, to address congestion on roadways throughout the city centre Stockholm considered implementing a cordon road pricing scheme. Due to the politically contentious nature of road pricing, and relative ease in creating a pilot program, Stockholm City Council implemented a 6-month charge period (Börjesson et al, 2007). Cordon pricing charges drivers who enter and exit the cordoned area located around the city centre. During the pilot, tolls were set at varying prices between 10 SEK, 15 SEK, or 20 SEK, with higher prices set for peak travel times (Eliasson, et al, 2009). Costs were applied for both directions passing the cordon with a maximum day charge of 60 SEK (Eliasson, et al, 2009). The system was created to provide 
short-term relief for congestion, creating more predictable travel times for drivers and allowing city officials an opportunity to study the potential of road pricing in a Stockholm setting.

Prior to the implementation of the pilot project, road pricing had low public support and was a politically contentious issue (Tristate Transportation Campaign, 2017). However, the temporary nature of a pilot allowed citizens and politicians to better understand the system's potential and the actual individual impacts, with the eventual ability to either accept or reject the project.

The pilot was successful at reducing traffic in the inner city and increased public acceptance. The pilot opened in January and decreased traffic by $28 \%$, with further decreases of $23 \%$ in February and 22\% in March, suggesting that road users overreacted initially before a more stable reduction was reached around 20-22\% (Börjesson et al, 2007). The overreaction to price and potential was extended toward public perception, which also saw improvement as charges were not as bad as originally feared (Börjesson et al, 2007).

Given the positive influence on congestion, in August 2007 Stockholm City Council reintroduced the cordon pricing scheme on a permanent basis (Börjesson et al, 2007). The rationale for making the pilot project permanent was to address longer term congestion reduction goals while providing revenue for maintenance of bridges and public transit improvements (Börjesson et al, 2007). The charge also looked to improve journey time through increasing reliability for drivers while also improving air quality and public health (Tristate Transportation Campaign, 2017). Framing the congestion charge through the green policy goals rather than as a tax instrument successfully decreased public opposition in other cities in Sweden that implemented similar pricing models (Börjesson and Kristoffersson, 2017). 
During the first year after permanent tolling, volumes of vehicles outside the cordon area increased, while traffic within the cordon area remained slightly below the $18 \%$ average set prior to the pilot toll in 2005 (Börjesson et al, 2007). In the subsequent years, traffic levelled around $20 \%$ below the 2005 volumes (Börjesson et al, 2007). Short-term effects were more impactful than long-term effects, which could be due to three reasons. The period of acclimatization may have been longer than 6 months, after which the charge was normalized and people paid it more often (Börjesson et al, 2007). Secondly, the decreases in congestion and increases in reliability may have made the charge more palatable for people with higher value of time (Börjesson et al, 2007). Thirdly, as public transportation is very developed in Stockholm and equates to around a $75 \%$ mode share for all trips, individual decisions to maintain preferred modes may not have been due to pricing of automobile use (Eliasson et al, 2013).

After 2007 and the permanent tolling implementation, revenue was roughly 500 million SEK per year. However, in 2016 the payment structure changed and influenced both revenues and congestion (Eliasson et al, 2013). The tolls increased to 35 SEK during peak hours, while periods outside these hours cost between 11-25 SEK (Tristate Transportation Campaign, 2017). Congestion within the inner city cordon stayed stagnant at a similar $20 \%$ reduction from pre-2005 values, but revenue capabilities changed greatly (Tristate Transportation Campaign, 2017). Revenue increased from 500 million SEK to roughly 1.3 billion SEK per year (Tristate Transportation Campaign, 2017). These benefits further contributed to public support of the project, a shift from high opposition to all pricing schemes at the start. Public support was uniquely positive due to congestion pricing exceeding anticipated benefits, and public costs lesser than what was first feared (Börjesson et al, 2007). Familiarity with the system and local 
ideology also played large roles, encouraging public acceptance by presenting the scheme as unavoidable. Furthermore, after the project was created and prices were set, it was understood that no major changes would be made (Börjesson et al, 2007).

The main purpose of the Stockholm congestion charge was to influence congestion and make automobile trips more predictable. While achieving this goal, the charge had become an effective revenue generation tool while also uniquely having high public support when compared to other road pricing initiatives around the world.

\subsection{Milan, Italy}

Similar to other large European cities, Milan had difficultly with increasing congestion within its city limits. However, Milan is unique in that half of its population owns cars or motorcycles, further increasing their use in the city (Percoco, 2013). This dominance has had subsequent effects on congestion, and more importantly on pollution levels. Due to this growth, Milan was found to have the third highest concentration of air pollution of all large Europe cities, with both the average annual and single-day concentration levels exceeding the limit considered safe by the European Union (EU) (Percoco, 2013). Prior to the implementation of road pricing, Milan averaged 125 days a year where pollution rose over the $50 \mu \mathrm{g} / \mathrm{m} 3$ limit from the EU, and averaged $51.2 \mu \mathrm{g} / \mathrm{m} 3$ annually (Rotaris et al, 2010).

High pollution levels in Milan have forced policy change and expanded potential for road pricing to play a mitigating role. National legislation required interventions to improve air quality no matter how drastic, with the ability to place temporary bans on all private vehicles travel to improve the air and environmental quality (Rotaris et al, 2010). This policy provision lowered the potential barriers for implementation of a road pricing scheme in Milan. 
In 2008, a pilot project known as Ecopass was created with a cordon area of $8^{2} \mathrm{~km}$ (Rotaris et al, 2010). To more effectively influence heavier polluting vehicles and have an immediate on effect lowering emissions, the structure of tolling targeted heavier polluting vehicles. The tolling charges for entering the cordon area were based on a vehicles emission class ranging from $€ 0, € 2, € 5$ or $€ 10$ per day, with charges enforced between 7:30 a.m. - 7:30 p.m. (Croci, 2016).

Prior to this road pricing scheme, 98,000 vehicles per month entered the cordon area. This number dropped to 82,200 during the first month of Ecopass operation (Percoco, 2013). Changes continued throughout the first year of the charge, decreasing congestion rates by $12.3 \%$ within the Ecopass area and by 3.6\% outside the Ecopass area (Rotaris et al, 2010). Temporal congestion changes also occurred, with the highest change of $23 \%$ between 7:30 a.m. and 8 a.m. and $17 \%$ during the rest of the charge period (Rotaris et al, 2010). After the start of the pricing scheme, lower emission vehicles increased in use. Due to the financial incentive of lower cost of use given a new pay-per-use scheme, the number of low-emission vehicles increased by $478 \%$ (Kodukula, 2013).

In conjunction with decreasing automobile use in the Ecopass area, city officials increased frequency of public transportation services, addressing increased demand from individuals who switched modes as a result from the toll (Rotaris et al, 2010). This public transportation change encouraged growth and predictability in both subways and surface-level routes. Subway use increased by $12.5 \%$, speed of subway service increased by $11.8 \%$, and average speed of surface level increased by 5\% (Kodukula, 2013). 
The decreases in congestion had short term-impacts for the ability of the Milan Ecopass scheme to reduce emissions inside the charged area and therefore had positive impacts on overall air quality. Particulate Mater or (PM) emissions were reduced by $15 \%$ in the Ecopass area and with marginal reductions of areas outside the Ecopass area when compared to pre-Ecopass levels (Kodukula, 2013). However, these effects were only temporary and short term, as a major flaw with the policy was the exclusion of motorcycles not being charged under pricing scheme (Percoco, 2013). With this exclusion, certain drivers were able to continue their use, which had subsequent effects on air quality and emissions.

To build the infrastructure required, an initial investment of $€ 7$ million was needed along with a further $€ 14$ million annual operation budget is funded by the scheme's revenue (Croci, 2016). This investment was lower than that of other large European initiatives given the smaller cordon area and the entry points to the charge area. By 2012, many of the higher-polluting vehicles were out of circulation, and emission levels were down from previously high levels. These successes encouraged a re-evaluation of the pricing scheme (Croci, 2016). The purpose of the pilot had been to minimize pollution, and had varying successes over different periods but provided evidence that potential exists. City Council approved a new scheme for permanent implementation, transitioning the main priority from pollution mitigation to congestion reduction (Croci, 2016). To address this change, the proposal included an expansion of the charge area ("Area C"), the same charging times, and a change for the fee structure with a flat $€ 5$ daily charge without the distinction of emission class included in Ecopass pricing (Croci, 2016).

Revenues increased with the changing payment structure and pricing area through the addition of Area C. Revenue grew from $€ 5.9$ million in 2011 to an annual average of $€ 27.1$ 
million from 2012 to 2014 (Croci, 2016). Daily traffic decreased by 30.7\% from averages

throughout the Ecopass period, with 41,000 fewer cars per day entering the charged area

(Kodukula, 2013). The Area $\mathrm{C}$ scheme increased effectiveness for congestion mitigation and

increased air quality by another $18 \%$ in the first year after the Ecopass period (Kodukula, 2013).

Road pricing in Milan transferred priorities from pollution reduction to congestion mitigation, and through this transition, had varying effects on congestion, pollution, and public transportation use.

Traffic reductions increased further with the incorporation of Area $\mathrm{C}$, which increased the size of the cordon. After this increase the scheme saw a further $37 \%$ decrease in traffic in the area compared to pre-2012 traffic levels (Croci, 2016). The decreases in congestion also encouraged decreasing emissions and had small mitigating effects on air quality as a result. The adoption of road pricing in Milan was closely tied to changing priorities as road pricing had differing effects based on the implemented charging methods. Milan was able to achieve positive effects on both emissions and pollution reduction, and limit congestion throughout both the Ecopass and additional Area $\mathrm{C}$ schemes while building upon previous successes to implement further action.

\subsection{International Case Studies — Common Themes and Lessons Learned}

Throughout the case studies, governments were able to take definitive action without addressing too many broad policy goals through one road pricing intervention. Addressing fewer issues allowed greater ability to achieve success in influencing positive change. Singapore specifically targeted road pricing toward congestion challenges. In doing so, pricing peak periods provided alternative resources with additional funding and congestion reduction within the CBD, but did not have a large impact on revenue generation. Similarly, Oslo wanted to impact both 
revenue generation and traffic reduction. Given that implementation characteristics would vary between these two different purposes and be less impactful for either, City Council designated its efforts toward revenue generation.

Milan proved that specific purposes rely on specific interventions. When first applied, road pricing was set up for reduction of emissions in the $\mathrm{CBD}$, which was reflected in the creation of specific tolling for vehicles based on emission class. This allowed a reduction of higher emitting vehicles through disincentive by price and thus incentivizing more environmentally-friendly vehicles. Success of the road pricing scheme forced a re-evaluation as air quality improved with higher polluting vehicles being slowly phased out. However, many relatively cleaner emitting cars still drove in the city centre and added to congestion. Milan then changed its road pricing scheme by changing both pricing and the area of focus, which provided definitive action for congestion mitigation and exemplified how interventions can be successful when addressing specific impacts rather than broad policy goals.

Road pricing interventions are a contentious issue to the general public - making it important to explore how negative opinion can be managed and minimized. In Bergen and Trondheim, governments were determined to implement road pricing for various reasons regardless of public opposition. For these cities, road pricing was used as a policy tool to achieve necessary funding for large infrastructure projects. Given Norway's high taxation and costs associated with car travel, citizens felt the additional costs were unnecessary and consequently a cost that should be borne by the state. Policy priorities related to sustainability trumped possible negative opinions from the public, while opposition was minimized through education and accountability. 
Similarly, to instil confidence in government officials, and by association road pricing schemes, Trondheim shut down its road pricing scheme after 15 years as originally promised. Road pricing had been contentious, but with an eventual end date the purpose was more apparent that revenue needed to pay for specific infrastructure projects would have to be generated within this time period. This scheme provided the public with knowledge of when pricing would end and understanding of the projects to which revenue would be directed, helping to reduce opposition. Thus, encouraging efficient policies to achieve this goal as an extension of road pricing would result in gain of public trust.

To contribute to the feasibility of road pricing schemes by reducing general opposition, all case studies examined and incorporated a reduced initial fee to minimize opposition. To reduce opposition, fees were created to stimulate and start benefits of road pricing, but by having a reduced effect on the users of the system. Naturally, the public will be hesitant to new policies that will cost them money. This thinking is based on how the policy might effect them, rather than what the policy actually achieves. These case studies showed that by implementing a lessened initial fee, users can better understand how the policy will affect them. By doing so, opposition was reduced in many cities as people better understood how the road pricing scheme worked and how they would be affected.

Lastly, most interventions incorporated specific provisions to divert revenue from road pricing to public transportation - leading to public trust in the benefits from these schemes. Mostly notably Oslo, Trondheim, Stockholm, and London used road pricing as a tool to prioritize public transportation use and dedicate additional funding towards increased service delivery. The additional funding helped create more viable systems, which distributed resources and created a 
more diverse transportation system. London had the most success with this intervention by identifying congestion as the main problem that roading pricing would address. Using $100 \%$ of the revenue generated from the scheme allowed London to address public transportation capacity and feasibility through the creation of new routes, bus-only lanes, and increased service, further contributing to a more comprehensive transportation system that works for more people. 


\subsection{The Bay Bridge Case Study}

Previous case studies have explored the potential of road pricing to address local planning issues. While those studies have been reviewed extensively for their successes and limitations, the Bay Bridge in San Francisco has been comparatively understudied. This study compiles information from policy documents, newspapers, and journal articles that explore congestion pricing in San Francisco.

Evidence from international case studies provide context and lessons for road pricing in San Francisco. Common themes outline the importance for governments to address specific impacts through road pricing. It is important that those do not address broad policy goals but rather specific goals and allow for the future adaption of road pricing structure. Similarly, given the contentious nature of implementing road pricing, strong political decision making is required. Minimizing public opposition is critical to the success of the prospect's long-term feasibility.

San Francisco and Oakland, the largest cities in northern California, are defined by their physical geography. Located among rolling hills, mountains, and water, the built environment has often been dictated by technology and engineering allowing the cities and region to prosper. In order to promote economic prosperity within the Bay Area, creating connections to neighbouring cities was at high importance throughout its developmental history. To address landmasses separated by water, multiple bridges were built around the region to strengthen connections, with the Bay Bridge playing an integral role in connecting the two most populous cities in the region. 


\subsection{Public Input}

Prior to the opening of the Bay Bridge on November 12th, 1936, many external planning factors had an impact on the construction and pricing structure in order for the bridge to be feasible (Weingroff 2017). To gain public acceptance of such a large and financially significant project, financial advantages were first outlined to the public. It was found that motorists would save thousands of dollars due to the lower fares on the bridge when compared to other comparative transportation modes (Weingroff, 2017). The tolls would allow the bridge to generate revenue, which could be used to pay for its construction. An important aspect of the pricing structure, however, was the ability to keep the tolls lower in comparison to other comparable transportation modes, which would therefore incentivize use of the bridge.

Public perception of road pricing on the proposed bridge was positive due to the increased connectivity while also allowing people to save money. Adopting road pricing as a tool for revenue generation from the creation of the bridge allowed the normalization of pricing for this specific route and placed additional pressure on politicians to approve such construction given the outlined benefits of such a plan. In comparison, political decision makers have faced large barriers imposing road pricing measures after roadways have been built and are free of charge to use, as outlined in international case studies (Leromonachou et al, 2006; Tristate Transportation Campaign, 2017; Börjesson et al, 2007). This has limited the number of roadways that are tolled throughout the world. However, in San Francisco public perception was vital to implementing road pricing on the Bay Bridge. 


\subsection{Policy Objectives}

Given the important role that the Bay Bridge plays, initial public policy objectives in 1932 focused on the road pricing as a tool to generate transportation infrastructure revenue rather than congestion alleviation (Weingroff, 2017). Compared with other services (e.g. a ferry), cost savings from the state-supported road tolls were significant. Governor James Rolph Jr, was a large proponent of the construction and amended the California Toll Bridge Authority Act to provide the ability for financing of state-owned bridges by revenue bonds in 1931 (Weingroff, 2017). Policy and politics are closely linked, and value judgments of decision making are closely tied to electability, or perceived reactions. The amendment and eventual road pricing scheme in San Francisco was unique due to the multiple levels of governments that supported the project which helped Governor Rolph Jr's eventual decision. The presumed benefits contributed to the potential for the Bay Bridge to be self-funding/revenue-generating through the possibility of different tolling measures.

To finance the upfront costs, it was proposed that California's share of the State gasoline tax allotment would provide the initial funds (Weingroff, 2017). Urban strategies to address funding generation vary depending on local values and political objectives. For the Bay Area, and the state of California, charging the users that will benefit from the new infrastructure was inherent in the policy and throughout the decision-making process. A variety of possible tolling strategies would then be used to pay back the initial funds. This strategy would allow the bridge to pay for itself after twenty years, and with plans for the bridge to be then free to use (Weingroff, 2017). However, once the original bonds were paid off, tolls on the bridge continued with varying pricing structures. This led to subsequent negative impacts on public perceptions of 
road pricing. With a steady stream of revenue, and a cost structure that was normalized to local populations, road pricing stayed in force despite prior intention for free use.

During the opening year in 1936, toll prices were set at $65 \mathrm{c}$, which were imposed on both directions of travel with toll booths collecting the fees (Metropolitan Transportation Commission, 2010). The 65c (USD\$11.93 with inflation) charge was soon decreased to 25c (\$4.17 with inflation) in 1941, which stayed stagnant until 1970. One-way tolling was then introduced for cars travelling westbound while east bound travellers did not incur a toll ("One Way Tolls to Start on Monday on All Bridges", 1969). This was intended to decrease administrative costs. San Francisco's lack of permeability for automobile travel, the travel patterns of local residents, and the city's role as an economic centre in the region, made it difficult to escape the toll in its entirety. To keep revenue generation at similar levels pre oneway collection, the toll price was doubled to 50c and this strategy proved important in its contribution to the current pricing structure of the bridge (Metropolitan Transportation Commission, 2010).

The toll price continued to rise incrementally from 50c in $1970,75 \mathrm{c}$ in 1978 , and $\$ 1$ in 1989 (Metropolitan Transportation Commission, 2010). During this time, funding was allotted to address the bridge's vulnerability to earthquakes, following the San Fernando Earthquake's destroying of bridges in Southern California (Office of Public Affairs, 1990). While addressing seismic design weaknesses, in 1989 the Loma Prieta earthquake hit, causing serious damage to the Bay Bridge and forced highway system management to research, to research long-term solutions. This had large implications on funding schemes (“1989”, 2018). 


\subsection{Post-Earthquake Seismic Retrofitting}

To address the long-term need for seismic retrofitting after the Loma Prieta major earthquake, in 1995 the California Department of Transportation or Caltrans began the process to build the necessary infrastructure through an investment of \$250 million, which was estimated to be adequate for both east and west spans of the bridge (Jaffe, 2015). However, the price drastically increased due to more detailed engineering studies were conducted in 1996, further raising the price to $\$ 1$ billion (Jaffe, 2015). The public perception of the project was greatly affected as these cost estimates climbed so significantly.

Further delays occurred as design preferences were discussed between two options: a basic skyway design and a tower design, with the latter seen as more favourable among government officials (Jaffe, 2015). Cost differences existed between the two designs and Governor Wilson saw the skyway option to be suitable for the needs of the bay without the additional costs associated with the design (Jaffe, 2015). Multiple designs were submitted to state legislator for funding, with an eventual $\$ 1.285$ billion allotted for the project under the tower design (Jaffe, 2015).

The budget to complete the project increased to $\$ 2.6$ billion as construction costs rose due to a strengthening economy, and with steel/concrete prices increasing (Jaffe, 2015). This delay was mainly due to the selection of the tower design, which had further effects on costs of construction than when first proposed (Jaffe, 2015). The necessary financing for completion of the project increased further from $\$ 5.5$ billion in 2005 to 6.5 billion in 2006 due to further delays and increasing insurance rates post 9/11, rise in steel prices, staffing requirements, and quality issues of outsourcing some of the construction to China (Jaffe, 2015). 
Pressure to fund the bridge's construction persisted even with increasing costs associated with its retrofitting due to the the 3.9 million cars that regularly travelled over the bridge monthly (Bayol, 2002). Government officials were pressured to fund the increasingly expensive project given the reliance of years of use and possible mode switch required if the bridge was not maintained.

In 2018, Governor Schwarzenegger addressed the bridge's financial needs through Assembly Bill 144, which provided a comprehensive plan to pay for the seismic retrofit ("How is the New Bay Bridge Being Financed”, 2018). In doing so, the bill provided $\$ 630$ million in state funding, while also authorizing the Bay Area Toll Authority (BATA) to increase tolls on all state owned bridges in the Bay Area. This created a solution for tolls to pay for outstanding costs not covered by the state of California ("How is the New Bay Bridge Being Financed", 2018).

The purpose behind road pricing measures and the subsequent allotment of revenue is dictated by local factors, and in this case study, revenue generation was a necessity. In San Francisco, Oakland, and the Bay Area, the purpose behind tolling was inherent in the ability for the bridge to be seismically retrofitted. Thus, it is necessary for road pricing to exist. Applying lowered fees to lower public opposition while still generating revenue was an important characteristic of the scheme. Revenue generation was important for paying off the debts associated with seismic retrofitting but also created a precedent and an ability to generate revenue for other purposes.

Prior to 2010, tolling on the Bay Bridge was based on a flat rate; however, in 2010, BATA introduced peak pricing to address congestion issues while providing revenue for the seismic retrofit that past policy has targeted. The tolling structure outlines peak periods from 5 a.m. - 10 
a.m., and 3 p.m. to 7 p.m., and times in between these as off-peak (Metropolitan Transportation Commission, 2019). BATA decided to price these differences at $\$ 7$ for peak, $\$ 5$ for off-peak, and \$6 for weekend travel (Metropolitan Transportation Commission, 2019). Although revenue of the Bay Bridge has been mainly focused on its potential of paying for the seismic retrofitting project, the peak pricing toll has various funding generation purposes.

The regular six-dollar toll is earmarked for four different purposes, which are redistributed around the Bay Area. The first dollar is earmarked for Regional Measure 1, which specifically includes bridge operations and maintenance projects, transit capital, and transit operations (Metropolitan Transportation Commission, 2019). The second dollar is earmarked to service debt on bonds that were issued for financing the seismic retrofitting. The third dollar, Regional Measure 2, is targeted towards a regional traffic relief plan that includes financing highways, transit, bicycle, and pedestrian projects in bridge corridors and their approaches, and operating funds for transit services (Metropolitan Transportation Commission, 2019). The fourth dollar is directed towards the seismic retrofitting program while the fifth dollar is directed specifically towards the seismic retrofit program of the nearby Antioch and Dumbarton bridges (Metropolitan Transportation Commission, 2019). Finally, the sixth dollar is earmarked to Regional Measure 3, which works to solve the Bay Area's congestion problems through financing of highway and transit improvements in the toll bridge corridors and other areas around the bay (Metropolitan Transportation Commission, 2019).

The main goals of the revenue diversion are seismic relief and regional measures including both public transportation infrastructure projects in San Francisco and Oakland as well as across the region. Addressing regional transportation allows the road charge benefits to apply 
to a wider area, contributing to a more holistic approach. However, with $50 \%$ of the tolling allotted toward seismic relief, the ability for the bridge's road pricing scheme to influence future congestion is limited.

The most recent data from 2014-2015 indicates that the Bay Bridge generated a road pricing revenue of $\$ 228,421,028$ USD, with $45,534,437$ cars travelling across the Bay Bridge (Historic Toll-Paid Vehicle Counts and Total Toll Revenues, n.d.), with all bridges across the Bay generating a further $\$ 720,784,303$ USD (Goodwin \& Rentschler, 2018). Use of the Bay Bridge is a major contributor for revenue generation for the Bay Area and therefore the pricing structure and use are closely connected. Volume and demand is necessary to fund seismic retrofitting and therefore pricing structures reflect the bridge's ability to generate revenue rather than possible contributions to other interventions such as congestion limitation or improvement of public transportation. Road pricing potential is therefore hindered until seismic retrofitting has been completed and the revenue stream is no longer needed for this specific purpose.

\subsection{Policy Shifts: Congestion Alleviation}

As the region continues to grow, pressures on transportation infrastructure increase and mode choice becomes increasingly important. In San Francisco, increased car travel has had negative impacts on travel speeds with increasing vehicle miles traveled (VMT) each year since 2011 (City of San Francisco, 2017). Subsequently, the increased VMT has affected congestion on freeway speeds around the city of San Francisco, as shown in a 10-year study by the San Francisco County Transportation Authority, which found that rush hour speeds for both arterial AM/PM and Freeway AM/PM travel speeds have decreased each year since 2009. The increased demand has placed additional pressures on corridors around the San Francisco area, and more 
specifically on the Bay Bridge. Car travel has become more prominent in San Francisco and use of the Bay Bridge after implementation of peak pricing is now more complex.

Peak pricing has had minimal influence on route choice; however, some change has occurred as people seek other options and travel on the fixed-rate tolling bridges around the bay. It was found that some drivers are substituting the Bay Bridge for the San Mateo Bridge, which lacks peak pricing, and this has subsequently contributed to the decrease in Bay Bridge traffic congestion (Foreman, 2016).

Time of use has been more easily influenced through the adaption of different pricing methods. Additionally, peak pricing had an effect on the demand curve, creating a more evenly distributed curve throughout the day but with increased volumes of travel (Barnes et al., 2012). Demand changes are now highest on the shoulders of peak times, with more people trying to travel on off-peak hours (Barnes et al., 2012). The more evenly-distributed volume suggests that overall use has not been impacted as much as what might have been intended. However, the ability to influence behaviour through cost can provide a benefit as seen in other locations, and through the malleability of impact that cost has had on the Bay Bridge in changing when people use the bridge.

Pricing corridors as seen on the Bay Bridge are an important tool in congestion reduction while providing funding opportunities for other more sustainable modes of transportation. The current structure of the road pricing scheme on the Bay Bridge is not impacting people's use of the bridge, but rather temporal changes in when people use it. For revenue generating purposes, the balance between use and congestion mitigation is important, due to the necessity for revenue generation to pay for outstanding and future debts. Facilitating this use is therefore inherent in 
the pricing model and is managed to facilitate this use. The current pricing structure therefore lacks the ability to mitigate volume and demand. 


\subsection{Conclusions and Lessons}

Road pricing on the Bay Bridge has been slowly adapted to address changing policy goals. Financial feasibility for the original construction relied heavily on the pricing model to create a structure for the bridge to be self-funding. Although the model was successful in generating the required revenue to fund the bridge's construction, modern seismic retrofitting needs were much more expensive when compared to the original construction. The need to generate revenue to fund seismic retrofitting placed additional pressures on the pricing structure to impact this specific goal. However, this policy would soon be deemed outdated as automobile congestion have risen since its implementation.

Increases in automobile congestion in the City of San Francisco are a newer trend that was not as prominent during the bridge's original 1930s construction. The current need for seismic relief makes adapting the pricing structure's intended effects on congestion measures difficult to incorporate since pricing is based on its original goal for the bridge to be self funding. Successes on congestion mitigation have therefore been muted. However, as seen in the lessons learned throughout the international case studies, potential currently exists and will exist in the future to adapt the pricing model to reflect changing policy goals. Clearly each policy context is different, as illustrated by each case study. Nevertheless, several lessons serve to highlight a range of changing challenges and approaches in San Francisco and in urban centres in general, which are relevant to cities considering congestion pricing. Specifically, three lessons are highlighted. 


\subsection{Lesson 1: Consistently adapt implementation strategies so they address changing issues}

The Bay Bridge illustrates how road pricing has has been and can be further adapted to changing policy needs. Due to the need for seismic relief in San Francisco, half of the revenue from the current road pricing structure has been diverted. Other interventions therefore cannot be adequately addressed until this specific project has been fully funded. Throughout the life cycle of pricing initiatives in San Francisco, slight adaption has allowed the ability for road pricing to serve multiple functions. However current needs in San Francisco to heavily prioritize funding generation over congestion mitigation, promoting volume on and around the Bay Bridge.

Vast potential exists in San Francisco to address congestion through road pricing as seen in the success of the London scheme. As learned, San Francisco should continue to adapt the current pricing model to place more emphasis on peak pricing. In doing so, diverting other revenue from the road pricing scheme to public transportation. This can have greater impact on current congestion levels while generating revenue for seismic relief. However, once major infrastructure projects are funded, adapting the pricing structure to reflect congestion mitigation and public transportation prioritization should be sought. The increased funding, in conjunction with other prioritization strategies such as dedicated surface level bus lanes, increasing routes, capacity, and frequency can encourage public transportation and are integral elements of such interventions.

Stagnant implementation characteristics are therefore not efficient and effective when applied to changing purposes. Changing purposes for road pricing require changing implementation characterizes which specialize and cater to more specific results. 


\subsection{Lesson 2: Public interest must be held in higher regard than electability}

Road pricing has been and continues to be contentious. As such, successful road pricing schemes have emerged from contexts which are successful in being both accountable and serving clear public interests - even if public support needs to be managed over time. Due to the contentious nature of road pricing, public opposition can be high which can have great influence on outcomes. In outlined case studies, and in San Francisco, politics played important roles for implementation, but some required politicians to make decisions which were not favourable among constituents. In many case studies, especially in Bergen, Oslo, Milan, and Stockholm, for road pricing to be implemented, politicians had to act on behalf of the collective public interest, which differed from original public views on road pricing. To achieve long term success and to achieve the policy goals sought, all the cities above incorporated various elements to promote acceptance.

The future of San Francisco road pricing relies heavily on this mitigation. To achieve policy goals overtime, the structure of road pricing will require politicians to consistently adapt and incorporate varying elements to minimize public opposition. Decisions that are made, may not be the most politically safe, but by serving the public interest, and being held accountable for decision making, long term success of road pricing can be achieved.

\subsection{Lesson 3: Mitigate Public Opposition Through Education of Purpose for Specific}

\section{Interventions}

Both clear communication of purpose and educating the public play key roles in managing public opinion about road pricing - even if public opinion never (or only slowly) views road pricing schemes favourably. 
In San Francisco, potential exists for encouraging acceptance. Historically there has been a mistrust between governments with original toll prices which paid for the bridge's original construction kept after necessary funding had been reached. Officials used the road pricing precedent to continue charging to use as a funding generation tool. Continuing to use road pricing to achieve policy objectives is not negative, however the process was not clear, nor was the public educated on the long term policy goals of keeping road pricing active.

In other case studies, especially in Stockholm, Bergen, Trondheim, Oslo, and London, governments specifically outlined the purpose of the funding, and how it would improve different aspects of daily life for the majority of people. Outlining the specific purpose is important as it allows the public to understand and hold governments accountable for subsequent use. Communication for the use of revenue was important, but major benefits occurred when individuals interacted the new infrastructure projects created from the result of increase of funding.

In San Francisco use of the bridge has been normalized, and other projects are not being impacted enough for citizens to see and understand the full scope of road pricing. Current use of toll funding can be found but is not easily understood by the general public due to the complexity of presentation. Similarly, once seismic relief projects are funded, as seen in the above case studies, diverting fundings to allow for greater investment in public transportation are vital. Educating and communicating to the public, the specific ways the increased funding is impacting public interest, is essential. This lesson has the potential to have mitigating impacts on public opposition while promoting the ability for road pricing to fully realize the various policy goals being addressed. 


\section{References}

Barnes, I., Trapenberg, K., Deakin, E \& Skabardonis, A. (2012). Impact of Peak and Off-Peak Tolls on Traffic in San Francisco-Oakland Bay Bridge Corridor in California. Transportation Research Board No. 2297. Pp. 73-79.

Bayol, G. (2002). San Francisco-Oakland Bridge East Span Seismic Safety Project. California Department of Transportation. Retrieved from: https:/web.archive.org/web/20110525033601/ http://www.dot.ca.gov/dist4/eastspans/spring02.html.

Bhatt, K., Higgins, T., Berg, J. (2008). Lessons Learned From International Experience in Congestion Pricing Final Report. U.S. Department of Transportation, Federal Highway Administration.

Börjesson, M \& Kristoffersson, I. (2017). The Swedish Congestion Charges: Ten Years On - And effects of increasing charging levels. VTI Swedish Road and Transport Research Institute.

Börjesson, M., Eliasson, J., Hugosson, M., Brundell-Freij, K. (2012). The Stockholm congestion charges -5 years on. Effects, acceptability and lessons learnt. Transport Policy. Vol. 20, Pp. $1-12$.

California Department of Transportation. (2018). How is the New Bay Bridge Being Financed? Retrieved from: https://www.baybridgeinfo.org/faq/how-new-bay-bridge-being-financed

California Department of Transportation. (2018). 1989. Retrieved from: https:// baybridgeinfo.org/1989.

City of San Francisco. (2017). San Francisco County Transportation Authority - Congestion Performance Scorecards. Retrieved from: https://sfgov.org/scorecards/transportation/congestion.

Croci, E. (2016). Urban road pricing: a comparative study on the experiences of London, Stockholm and Milan. Transportation Research Procedia. Vol, 14. Pp. 253-262.

De Palma, A. \& Lindsey, R. (2009). Traffic Congestion Pricing Methods and Technologies. hal-00414526

Eliasson, J., Hultkrantz, L., Nerhagen, L., Rosqvist, L. (2009). The Stockholm congestioncharging trial 2006: Overview of effects. Transportation Research Part A43. Pp. 240-250.

Eliasson, J., Börjesson, M., Amelsfort, D., Brundell-Freij, K, Engleson, L. (2013). Accuracy of congestion pricing forecasts. Transportation Research Part A: Policy and Practice. Vol. 52. Pp. 34-46. 
Foreman, K. (2016). Crossing the bridge: The effects of time-varying tolls on curbing congestion. Transportation Research Board Part A 92. Pp. 76-94.

Gómez-Ibáñez, J. \& Small, K. (1994). Road Pricing for Congestion Management: A Survey of International Practice.

Goodwin, P. (1989). The 'Rule of Three': A Possible Solution to the Political Problem of Competing Objectives for Road Pricing. Traffic Engineering + Control. Vol 30. No 10. Pp. 495-497.

Goodwin, J. \& Rentschler, R. (2018). Tolls on Seven Bay Area Bridges Set to Rise Next Month. Metropolitan Transportation Commission. Retrieved from: https://mtc.ca.gov/whats-happening/ news/tolls-seven-bay-area-bridges-set-rise-next-month.

Jaffe, E. (2015). From \$250 Million to \$6.5 Billion: The Bay Bridge Cost Overrun. Retrieved from: https://www.citylab.com/equity/2015/10/from-250-million-to-65-billion-the-bay-bridgecost-overrun/410254/.

Kodukula, S. (2013). The Ecopass pollution charge and Area C congestion charge - comparing experiences with cordon pricing over time.

Leape, J. (2006). The London Congestion Charge. Journal of Economic Perspectives. Vol. 20, N. 4, Pp. 157-176.

Lindsey, R. (2006). Do Economists Reach A Conclusion of Road Pricing? The Intellectual History of an Idea. Econ Journal Watch, Vol. 3 No. 2, Pp. 292-379.

Litman, T. (2011). London Congestion Pricing. Victoria Transport Policy Institute.

Metropolitan Transportation Commission. (n.d.) Historic Toll-Paid Vehicle Counts and Total Toll Revenues. Retrieved from: https://mtc.ca.gov/about-mtc/what-mtc/mtc-organization/threeagencies-one/bay-area-toll-authority/historic-toll-paid.

Metropolitan Transportation Commission. (2010.) History of California's Bridge Tolls. Retrieved from: https://mtc.ca.gov/sites/default/files/toll_history.pdf.

Metropolitan Transportation Commission. (2019) Toll Funded Investments. Retrieved from: https://mtc.ca.gov/our-work/invest-protect/toll-funded-investments.

Leromonachou, P., Potter, S., Warren, J.P. (2006). Norway's urban toll rings: Evolving towards congestion charging? Transport Policy, Vol. 13, Pp. 367-378.

Lian, J. (2008). The Oslo and Bergen toll rings and road-building investment-Effect on traffic development and congestion. Journal of Transport Geography. Vol. 16, Pp. 174-181. 
One Way Tolls to Start on Monday on All Bridges. (1969). The Argus from Fremont, California. Office of Public Affairs. (1990). Loma Prieta Earthquake: Collapse of the Bay Bridge and the Cypress Viaduct. US Government Accountability Office. Retrieved from: https://www.gao.gov/ products/rced-90-177.

Percoco, M. (2013). Is road pricing effective in abating pollution? Evidence from Milan. Transportation Research. Part D. Vol. 25, Pp. 112-118.

Rotaris, L., Danielies, R., Marcucci, E., Massiani, J. (2010). The urban road pricing scheme to curb pollution in Milan, Italy: Description, impacts and preliminary cost-benefit analysis assessment. Transportation Research Part A. Vol. 44, Pp. 359-375.

Tretvik, T. (2007 June). End of 15 years of urban road user charging in Trondheim, NorwayWhat now? Presented at the 11th World Conference on Transport Research (WCTR) Berkeley, California. Retrieved from: http://citeseerx.ist.psu.edu/viewdoc/download? doi $=10.1 .1 .611 .2213 \&$ rep $=$ rep $1 \&$ type $=$ pdf.

Tristate Transportation Campaign. (2017). Road Pricing in London, Stockholm, and Singapore. A way forward for New York City. Retrieved from: http://www.tstc.org/reports/A-WAYFORWARD-FOR-NEW-YORK-CITY-2017.pdf.

Walters, A. (1961). The Theory and Measurement of Private and Social Cost of Highway Congestion. Econometrica Vol. 29, No. 4. Pp. 676-699.

Wærsted, K. (2005). Urban Tolling in Norway - Practical Experiences, Social and Environmental Impacts and Plans for Future Systems. Retrieved from: https://www.piarc.org/ ressources/documents/281,2.1-Waersted-0405C11.pdf.

Weingroff, R. (2017). Two Bay Area Bridges - The Golden Gate and San Francisco-Oakland Bay Bridge. Retrieved from: https://www.fhwa.dot.gov/infrastructure/2bridges.cfm. 